\title{
Efficacy of riluzole in the treatment of spinal cord injury: a systematic review of the literature
}

\author{
Shanmukha Srinivas, BS, Arvin R. Wali, MD, MAS, and Martin H. Pham, MD \\ Department of Neurosurgery, University of California San Diego School of Medicine, San Diego, California
}

OBJECTIVE Riluzole is a glutamatergic modulator that has recently shown potential for neuroprotection after spinal cord injury (SCl). While the effects of riluzole are extensively documented in animal models of $\mathrm{SCl}$, there remains heterogeneity in findings. Moreover, there is a paucity of data on the pharmacology of riluzole and its effects in humans. For the present study, the authors systematically reviewed the literature to provide a comprehensive understanding of the effects of riluzole in $\mathrm{SCl}$.

METHODS The PubMed database was queried from 1996 to September 2018 to identify animal studies and clinical trials involving riluzole administration for $\mathrm{SCl}$. Once articles were identified, they were processed for year of publication, study design, subject type, injury model, number of subjects in experimental and control groups, dose, timing/route of administration, and outcomes.

RESULTS A total of 37 studies were included in this study. Three placebo-controlled clinical trials were included with a total of 73 patients with a mean age of 39.1 years (range 18-70 years). For the clinical trials included within this study, the American Spinal Injury Association Impairment Scale distributions for SCI were $42.6 \%$ grade A, 25\% grade B, 26.6\% grade $\mathrm{C}$, and $6.2 \%$ grade $\mathrm{D}$. Key findings from studies in humans included decreased nociception, improved motor function, and attenuated spastic reflexes. Twenty-six animal studies (24 in vivo, 1 in vitro, and 1 including both in vivo and in vitro) were included. A total of 520 animals/in vitro specimens were exposed to riluzole and 515 animals/in vitro specimens underwent other treatment for comparison. The average dose of riluzole for intraperitoneal, in vivo studies was 6.5 $\mathrm{mg} / \mathrm{kg}$ (range 1-10 mg/kg). Key findings from animal studies included behavioral improvement, histopathological tissue sparing, and modified electrophysiology after SCl. Eight studies examined the pharmacology of riluzole in SCl. Key findings from pharmacological studies included riluzole dose-dependent effects on glutamate uptake and its modified bioavailability after $\mathrm{SCl}$ in both animal and clinical models.

CONCLUSIONS SCI has many negative sequelae requiring neuroprotective intervention. While still relatively new in its applications for $\mathrm{SCl}$, both animal and human studies demonstrate riluzole to be a promising pharmacological intervention to attenuate the devastating effects of this condition.

https://thejns.org/doi/abs/10.3171/2019.1.FOCUS18596

KEYWORDS riluzole; spinal cord injury; neuroprotection; excitotoxicity; review

$\mathrm{S}$ PINAL cord injury (SCI) remains a devastating problem, with traumatic SCI affecting 12,400 individuals annually and 250,000 living survivors reported to reside in the United States in July $2005 .{ }^{13}$ The prevalence of nontraumatic SCI is estimated to be 3-4 times greater than traumatic SCI. ${ }^{36}$ A variety of complications, including genitourinary and respiratory complications, often occur after SCI with rehospitalization rates of up to $55 \%$ in the 1st year after SCI and around 37\% for every year thereafter for 20 years. ${ }^{8}$ Moreover, while $58.1 \%$ of patients are employed before injury, only $12.1 \%$ remained employed 1 year after injury. As a manifestation of both indirect and direct cost, patients sustaining an SCI at age 25 years can expect a lifetime cost of $\$ 4.6$ million for high tetraplegia and $\$ 2.3$ million for paraplegia. ${ }^{13}$ There remains a need to improve recovery after SCI, considering its high incidence and these associated complications.

The pathophysiology involved in SCI includes multiple mechanisms such as the shearing of axons ${ }^{45}$ followed by neural death due to ischemia, ${ }^{28}$ production of inflamma-

ABBREVIATIONS AIS = American Spinal Injury Association Impairment Scale; ALS = amyotrophic lateral sclerosis; SCI = spinal cord injury.

SUBMITTED October 31, 2018. ACCEPTED January 2, 2019.

INCLUDE WHEN CITING DOI: 10.3171/2019.1.FOCUS18596. 
tory molecules, ${ }^{12}$ and the rise of extracellular glutamate contributing to excitotoxicity. ${ }^{43}$ Current acute management strategies of SCI include surgical decompression, ${ }^{19}$ maintenance of arterial pressure with fluids and vasoconstrictors, ${ }^{52}$ and methylprednisolone, an antiinflammatory corticosteroid that inhibits transmigration of neutrophils and macrophages into the spinal cord, thereby reducing peroxidation of lipids in the cell membrane. ${ }^{3}$ However, there remains a need for greater neuroprotective agents to promote long-term recovery after SCI.

Riluzole, a glutamatergic modulator used primarily in amyotrophic lateral sclerosis (ALS), ${ }^{26}$ is currently being evaluated for use in SCI. Riluzole activates guanosine triphosphate-binding signal transduction proteins (G-proteins), resulting in inhibition of neurotransmitter release. ${ }^{14}$ Riluzole also indirectly inhibits phospholipase A2 (PLA2), preventing release of arachidonic acid, and directly inhibits protein kinase $\mathrm{C}$ (PKC). ${ }^{42}$ Recent studies have suggested that riluzole is neuroprotective in neurodegenerative and traumatic injuries through its blockade of sodium channel overactivation and modulation of glutamate uptake, ${ }^{4}$ as well as its stimulation of brain-derived neurotrophic factor expression. ${ }^{29}$ The use and effects of riluzole specifically in SCI, however, remain relatively new.

In this article, we aim to provide an overview of riluzole's potential effectiveness in SCI and review current pharmacological, animal study, and clinical trial findings with this treatment.

\section{Methods}

A systematic review to analyze the use of riluzole in SCI was performed through PubMed with articles dating from 1996 to September 2018 (Fig. 1). The search term was "riluzole Spinal Cord Injury." This search yielded 99 results. Articles were included within this review if they presented primary human or animal data or investigated the pharmacology of riluzole in spinal cord injury. By this method, 37 experimental studies met the inclusion and exclusion criteria.

The extracted articles were then divided into 3 categories: 1) animal studies describing therapeutic benefit, 2) clinical studies describing outcomes, and 3) pharmacological studies. Two studies contributed findings to both pharmacology and therapeutic benefit in animals. ${ }^{39,58}$ Animal studies were evaluated for study design (in vivo vs in vitro); animal type; injury model; number of animals included in experimental and control groups; dose; timing and route of administration; and outcomes measured by behavior, histopathology, and electrophysiology. Clinical trials were reviewed for study design, number of patients in experimental and control groups, SCI level, American Spinal Injury Association Impairment Scale (AIS) grade, average age, timing and route of administration, dosage, adverse events, and outcomes measured by sensory and motor functional tests. Pharmacological studies were evaluated for study design, subject type, injury model, number of patients in experimental and control groups, timing and route of administration dosage, adverse effects and outcomes measured by electrophysiology, neurotransmitter uptake, receptor expression, and pharmacokinetics.

\section{Results}

\section{Pharmacological Studies}

Despite extensively published research on the pharmacology of riluzole, there are few studies reporting its effects on SCI. In this review, 8 studies on the pharmacological effect of riluzole in SCI were included. Pharmacological studies described the mechanisms of action and pharmacokinetics of riluzole in vivo, in vitro, and in human studies. The major findings included decreased riluzole bioavailability in the spinal cord after SCI ${ }^{10,15}$ with 1 study suggesting the opposite ${ }^{58}$ blockage of sodium currents with riluzole after SCI ${ }^{25}$ and increase in glutamate uptake and expression, $, 38,53$ with 1 study suggesting no effect of riluzole on glutamate release after SCI. ${ }^{35}$ A full description of the pharmacology articles within this study can be found in Table 1.

\section{Animal Studies}

Twenty-six animal studies describing the therapeutic effects of riluzole after SCI were included. There were 24 in vivo studies, 1 in vitro study, and 1 mixed study. A total of 520 animals/in vitro specimens were exposed to riluzole and 515 animals/in vitro specimens underwent other treatments for comparison. The average dose of riluzole used was $6.5 \mathrm{mg} / \mathrm{kg}$ in 7 in vivo studies in rats with predominantly intraperitoneal administration, with a few exceptions instead involving intrathecal and intracerebroventricular ${ }^{24}$ or intravenous administration ${ }^{33}$ and rabbits. ${ }^{31-33,39}$ For behavioral studies, locomotion was evaluated with the rotarod, grid walk, open field, and pelletreaching tasks; strength was evaluated with the inclined plane test; and sensory function was evaluated with the hind paw withdrawal test. A plethora of behavioral studies demonstrated positive effects of riluzole on motor function including locomotion, ${ }^{21,27,34,38,48,58,57}$ strength, ${ }^{1,47,48}$ and stance and stride length. ${ }^{47,49}$ With regard to sensory function, behavioral studies have suggested that riluzole decreases nociception ${ }^{24}$ and spastic reflexes, ${ }^{30}$ which is both encouraging for reduction of neuropathic behaviors and concerning for decreased response to noxious stimuli. Histopathological experiments have shown that after SCI, riluzole increased rostrocaudal and epicenter tissue sparing with decreased lesion volume, increased axonal sparing, and increased serotonergic fibers. ${ }^{38,48,55}$ Other studies have shown an increase in glial cell and neuronal survival, ${ }^{6,34,44,58}$ decrease in reactive oxygen species, ${ }^{49}$ increase in synaptophysin expression in the ventral horn ${ }^{47}$ decrease in capillary fragmentation, ${ }^{50}$ decrease in pyknosis and hypoplasia of ventral motor neurons, ${ }^{49}$ decrease in lymphocytes and granulocytes, ${ }^{7}$ increase in choline acetylcholine transferase staining in motor neurons ${ }^{21}$ decrease in lactate dehydrogenase ${ }^{23}$ decrease in TUNEL staining apoptotic neurons, ${ }^{32,58,57}$ decrease in macrophages and microglia ${ }^{58}$ and decrease in lipid peroxidation and water content. ${ }^{1}$ Electrophysiological experiments have suggested a decrease in muscle spasm, ${ }^{5}$ attenuation of altered reflex mechanisms ${ }^{47}$ and increase in amplitude of somatosensory evoked potentials. ${ }^{58}$ Key findings within the animal data demonstrate spinal cord tissue sparing with cell survival after SCI, ${ }^{1,6,33,31-34,38,39,41,44,46,48,55,57,58}$ reduced inflam- 


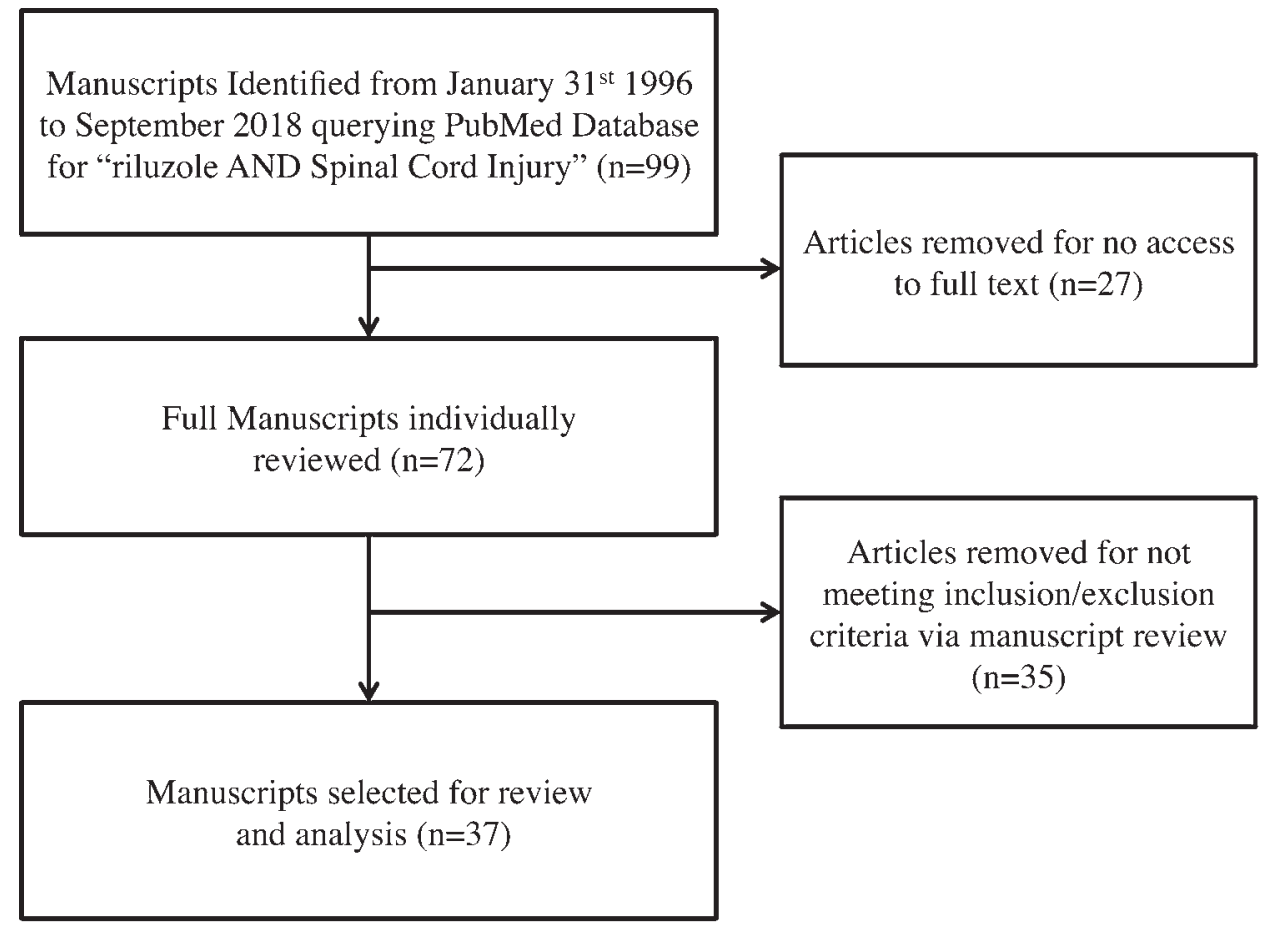

FIG. 1. Ninety-nine clinical studies regarding the use of riluzole in spinal cord injury were initially identified. Twenty-seven articles were removed for inadequate access to the full article. Seventy-two papers were fully reviewed. After applying inclusion and exclusion criteria, 37 articles were selected for review and analysis.

matory mediators and sequelae, 7,49 improved locomotion, $, 1,7,21,27,30,31-34,38,44,49,55$ and decreased aberrant sensory responses. ${ }^{5,24}$ A full description of animal studies and the results from these investigations can be found in Table 2 .

\section{Human Clinical Studies}

Three clinical studies were included in this systematic review. The average age of the patients was 39.1 years (range 18-70 years). In total, the percentage of patients included by AIS grade was $42.6 \%$ grade A, $25 \%$ grade $\mathrm{B}, 26.6 \%$ grade $\mathrm{C}$, and $6.2 \%$ grade $\mathrm{D}$. Most patients in the clinical studies included were severely impaired at baseline. The major findings from clinical studies included decreased pain, ${ }^{37}$ increased motor functionality, ${ }^{22}$ and decreased spastic reflexes ${ }^{54}$ after administration of riluzole for SCI. Specifically, with regard to motor function, Meshkini et al. ${ }^{37}$ and Grossman et al. ${ }^{22}$ demonstrated statistically significant general motor improvement with riluzole at 6 and 3 months after acute SCI, respectively, while Theiss et al. ${ }^{54}$ showed strong correlation of riluzole use with lower-limb volitional strength for patients with chronic, incomplete SCI. Of the 3 clinical studies included, only Meshkini et al. ${ }^{37}$ evaluated reduction in pain after riluzole use, and only Theiss et al. ${ }^{54}$ evaluated attenuation of spastic reflexes. Clinical studies consistently demonstrated incomplete recovery after SCI despite the use of riluzole as manifested by low motor ${ }^{10,37}$ and sensory ${ }^{37}$ scores as well as debilitated voluntary contraction..$^{54}$ All patients in clinical studies were administered $50 \mathrm{mg}$ of riluzole enterally. However, while Meshkini et al. ${ }^{37}$ and Grossman et al. ${ }^{22}$ included a longitudinal dose of $50 \mathrm{mg}$ BID (twice daily) for
8 and 4 weeks, respectively, Theiss et al. ${ }^{54}$ only included a one-time dose of $50 \mathrm{mg}$ before testing. Overall, riluzole showed promising results with a decrease in neuropathic pain and severity of SCI, ${ }^{37}$ increase in motor function ${ }^{22}$ for cervical injury, and decrease in spasticity with preservation of normal voluntary movement. ${ }^{54}$ However, these benefits were not without risk for complications, as $14 \%-$ $70 \%$ of patients in the Grossman study had elevated liver enzymes and bilirubin levels, implying potentially hepatotoxic effects of riluzole in humans. ${ }^{22} \mathrm{~A}$ full description of clinical studies included within this analysis can be found in Table 3.

\section{Discussion}

This systematic review describes the potential use of riluzole for efficacy after SCI in humans and animals in improving functional and neurological outcomes after SCI, including positive neuroprotective results. ${ }^{18}$ Primary and secondary damage in SCI is mediated primarily by excitotoxicity ${ }^{16}$ and thus riluzole, a prominent antiglutamatergic agent ${ }^{56}$ has been a treatment of interest for SCI. Increased expression of glutamate transporters (EAAC1, GLST, and GLT-1) has been implicated in SCI with riluzole treatment increasing uptake activity of glutamate and attenuating any neuropathic pain sequelae from SCI. ${ }^{53}$ Moreover, riluzole blocks persistent inward sodium currents and fast sodium spikes, which are particularly important in chronic SCI. ${ }^{25}$ There is now a consensus that in neurodegenerative disorders, riluzole works predominantly through increasing glutamate uptake in astrocytes and presynaptic neurons, 


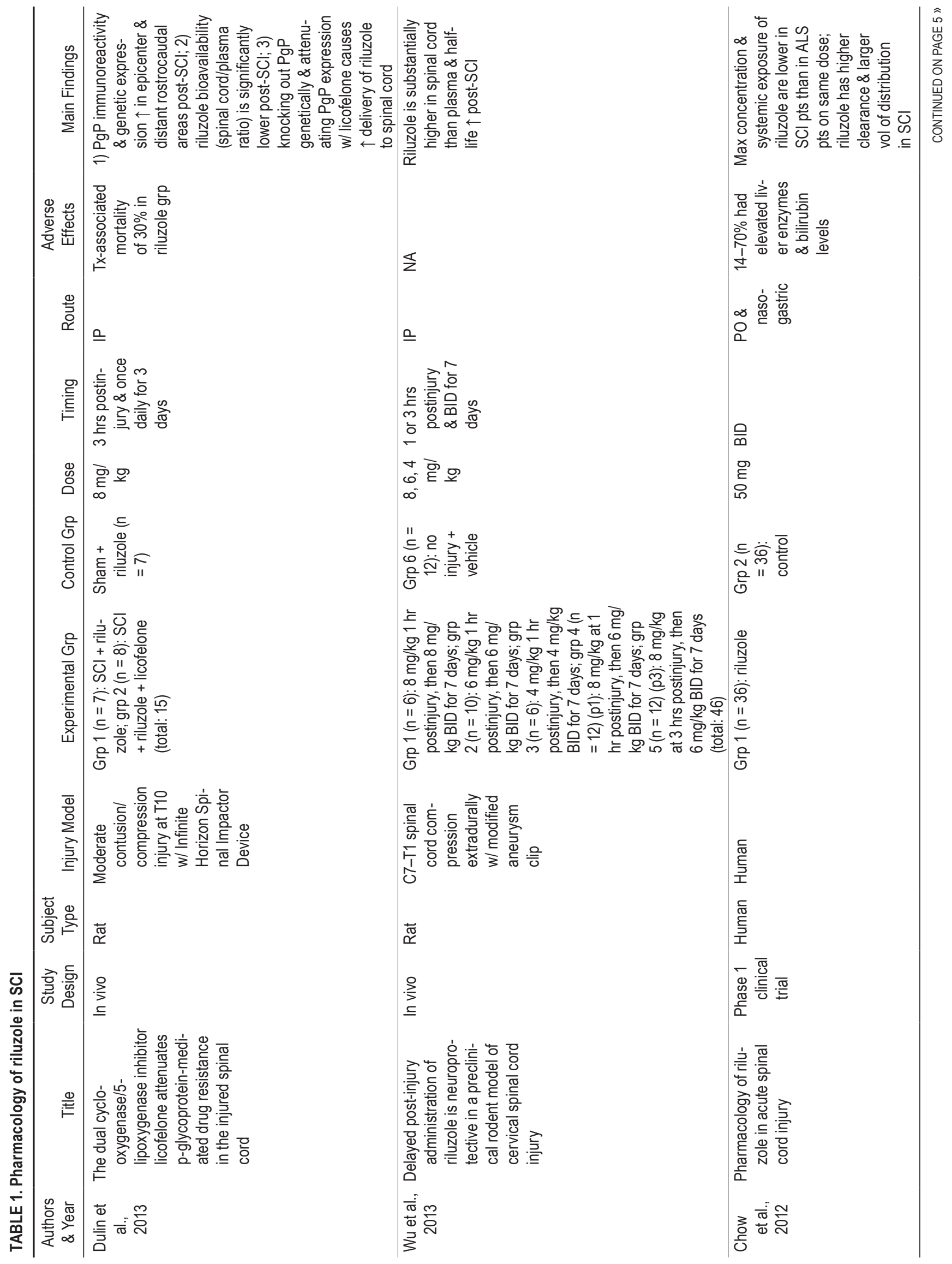




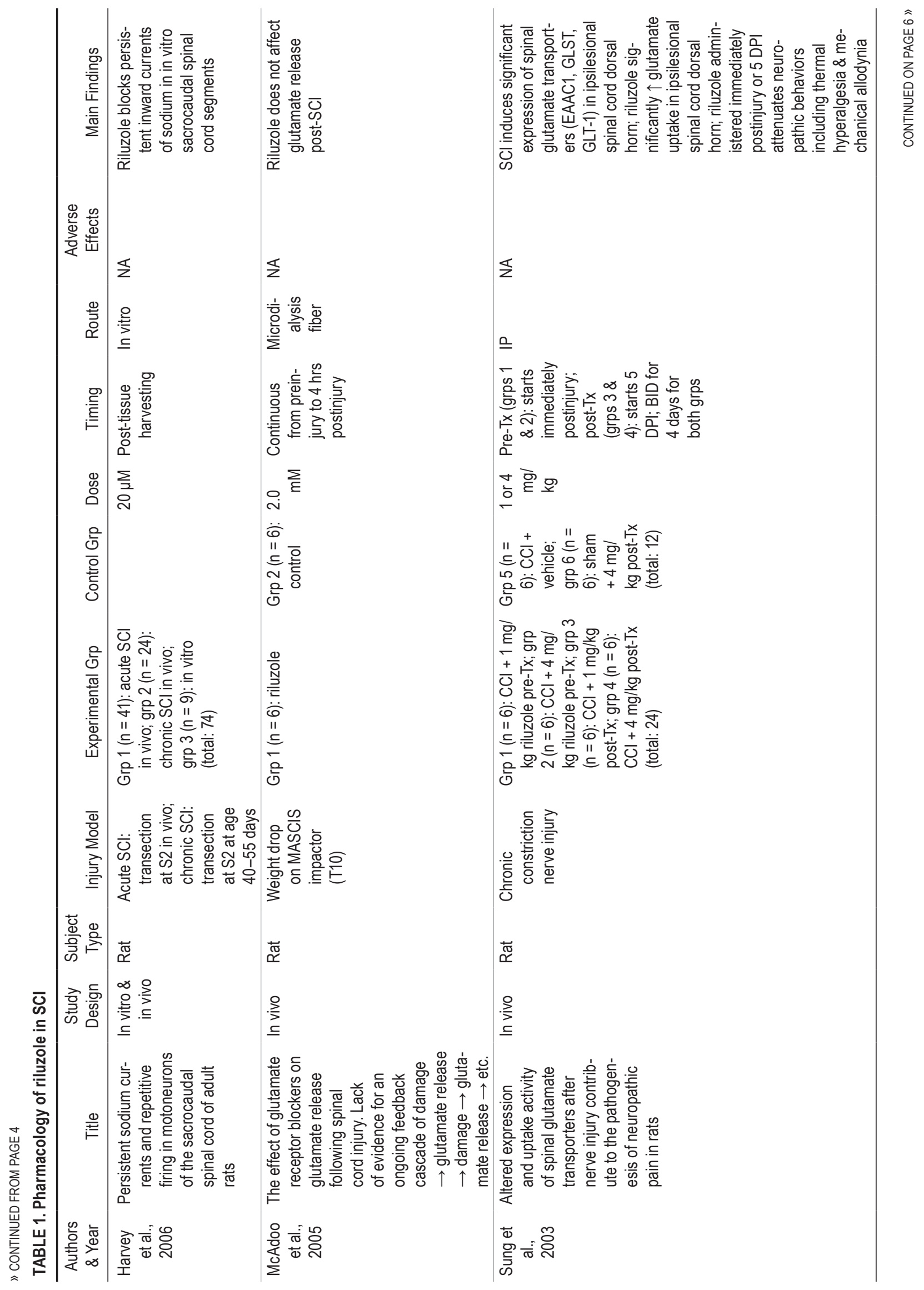




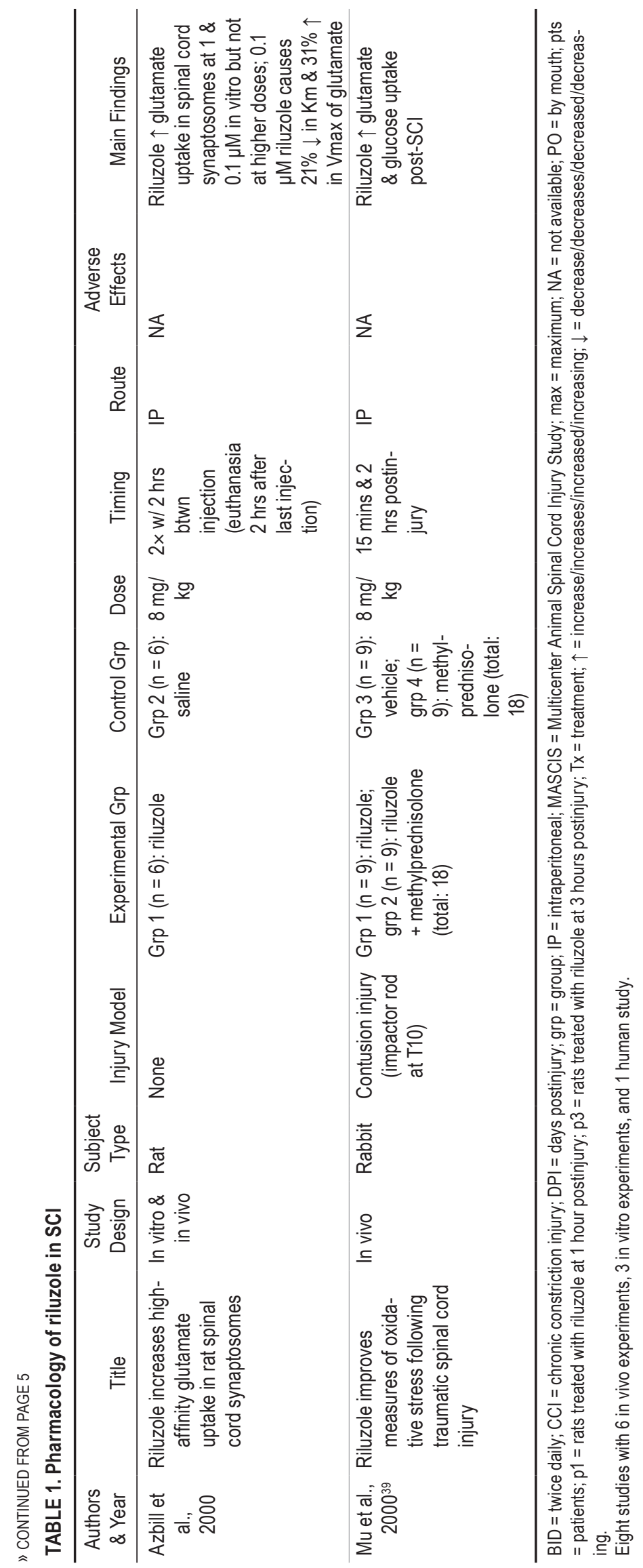




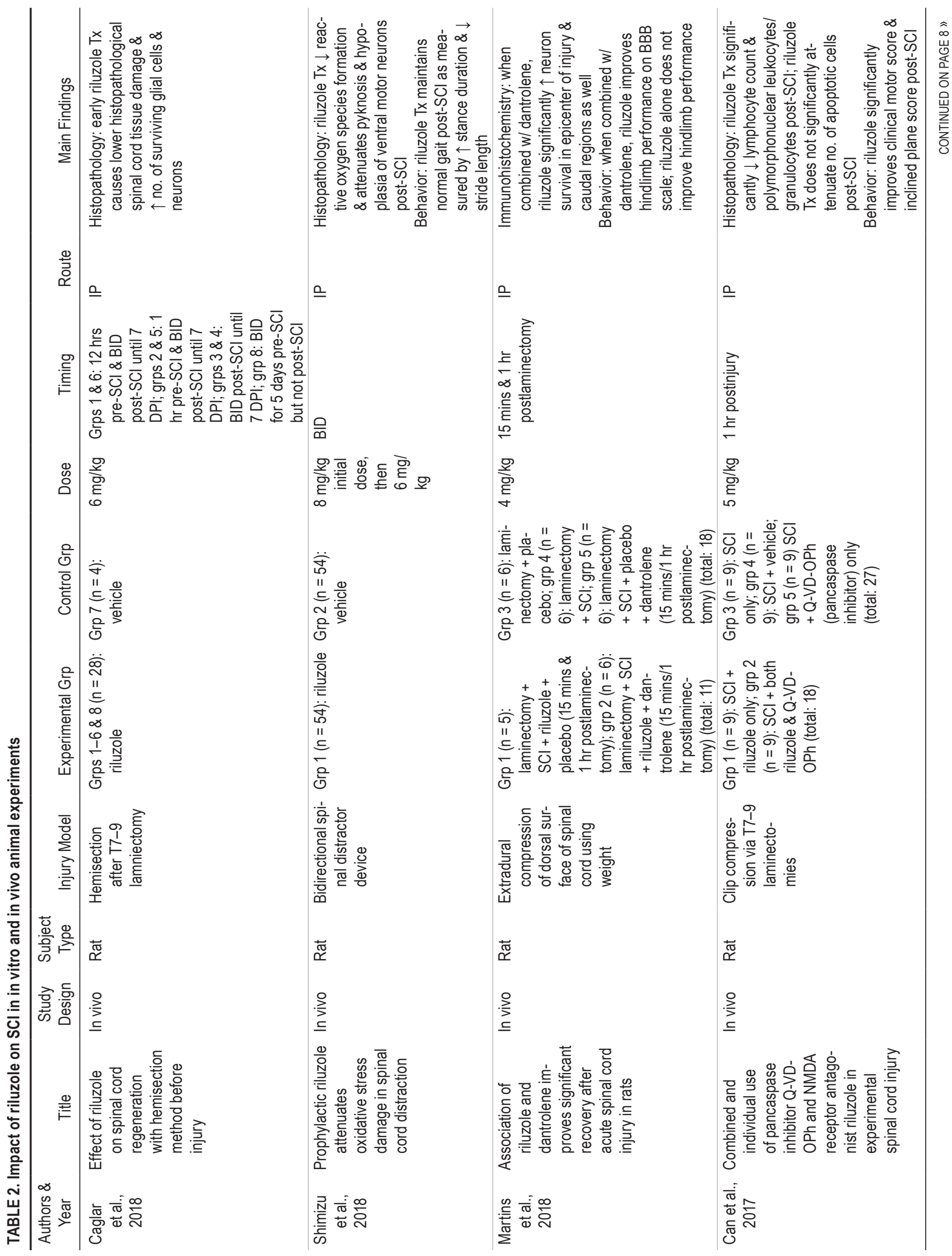




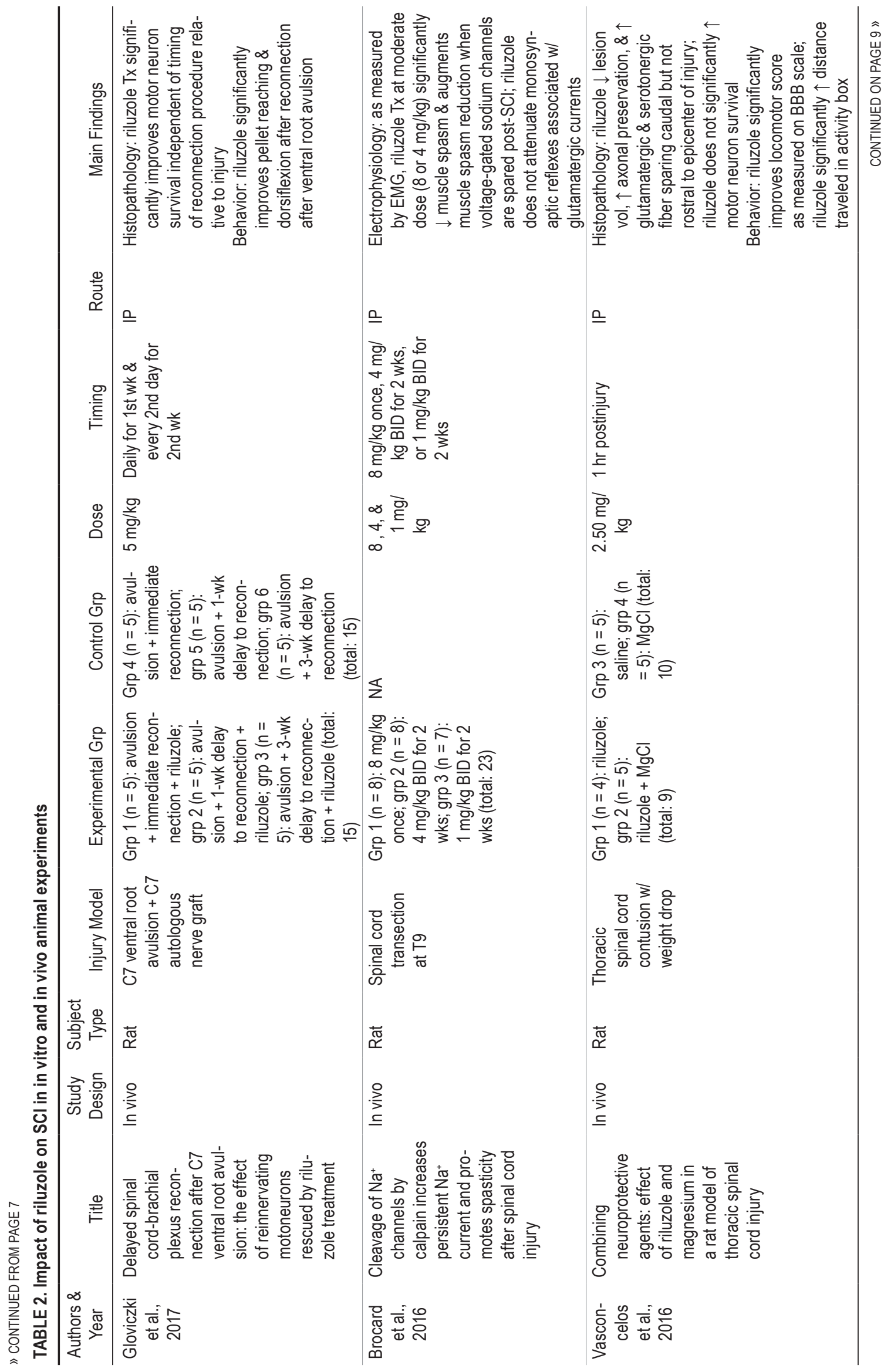




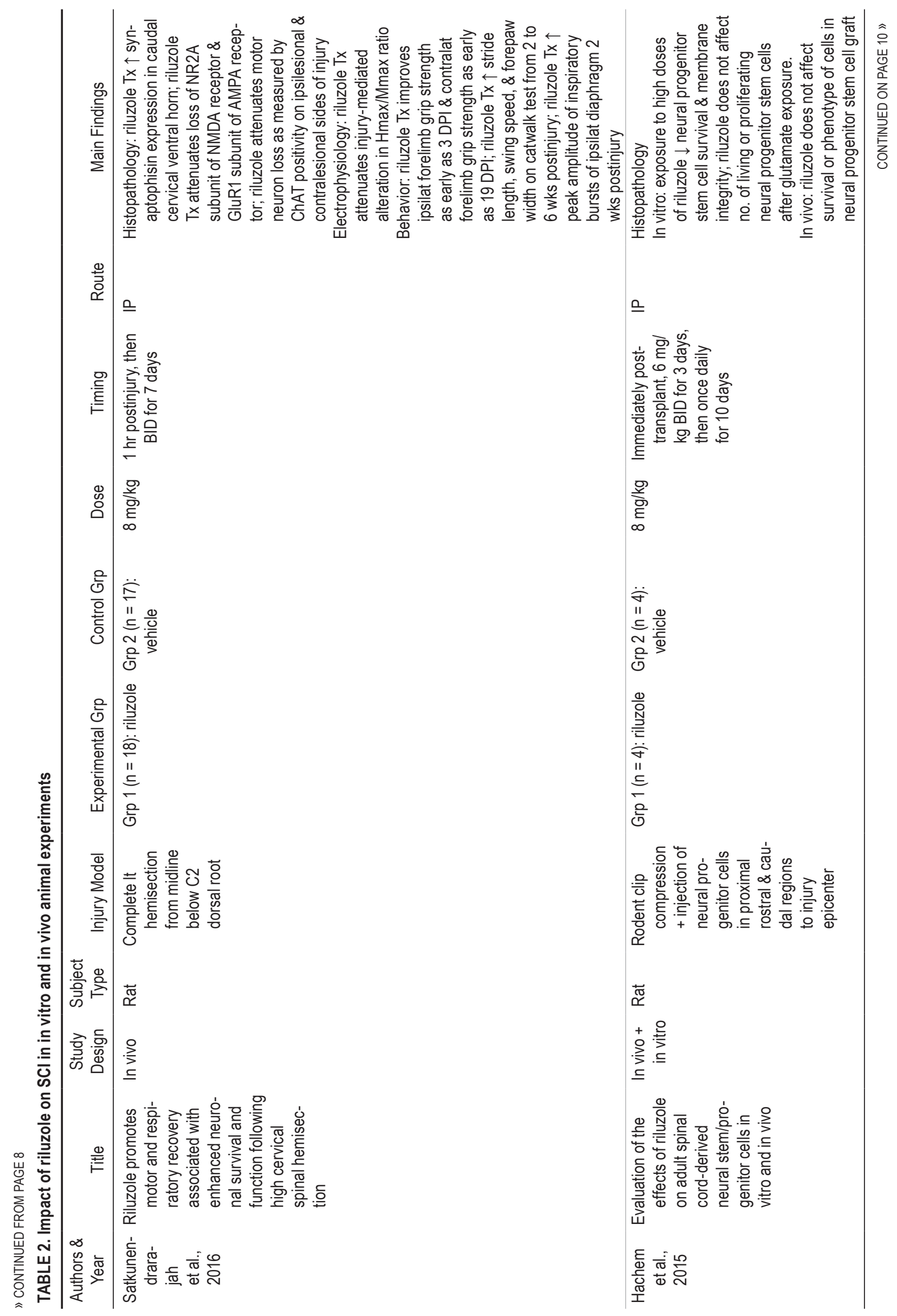

Neurosurg Focus Volume 46 • March 2019 


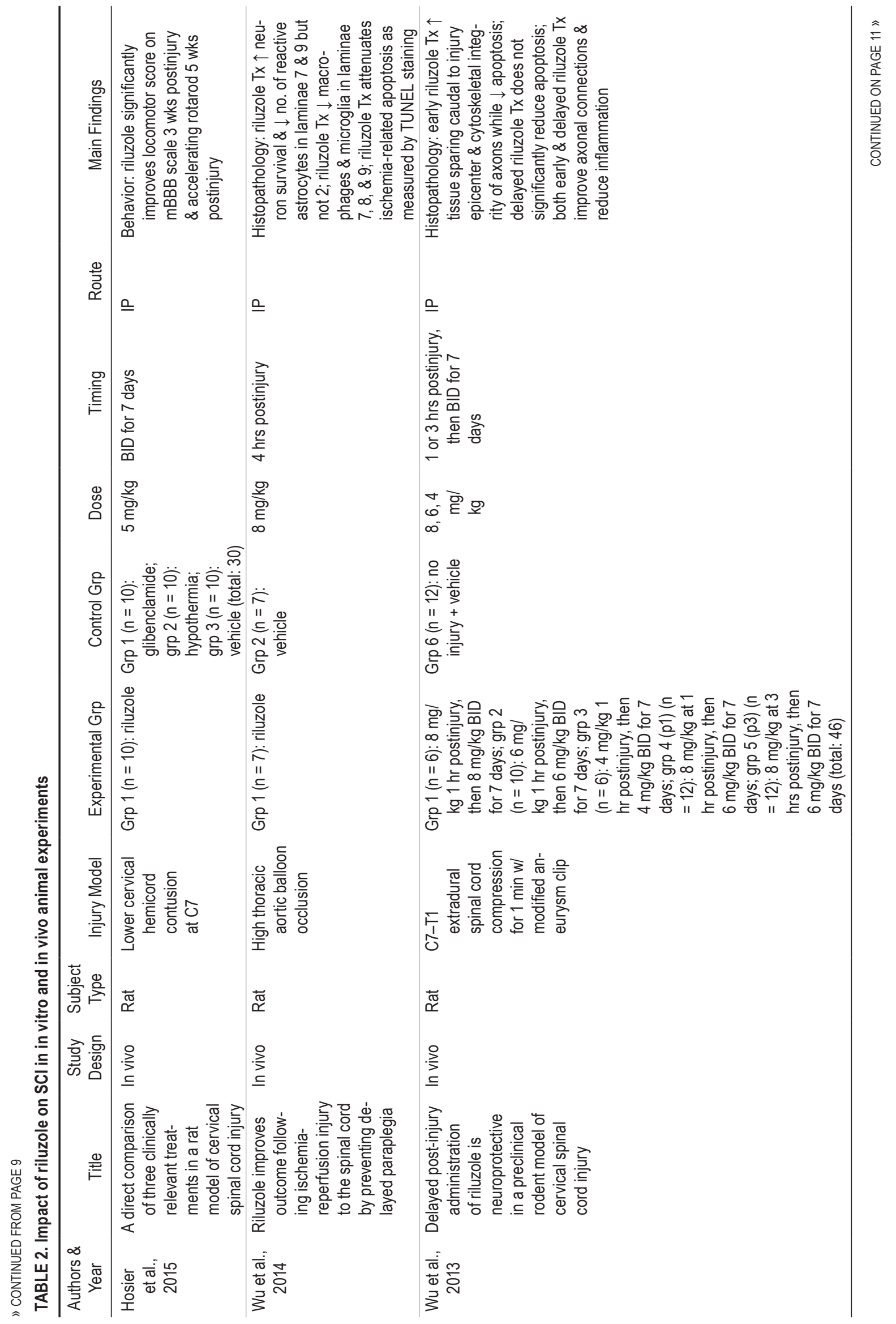




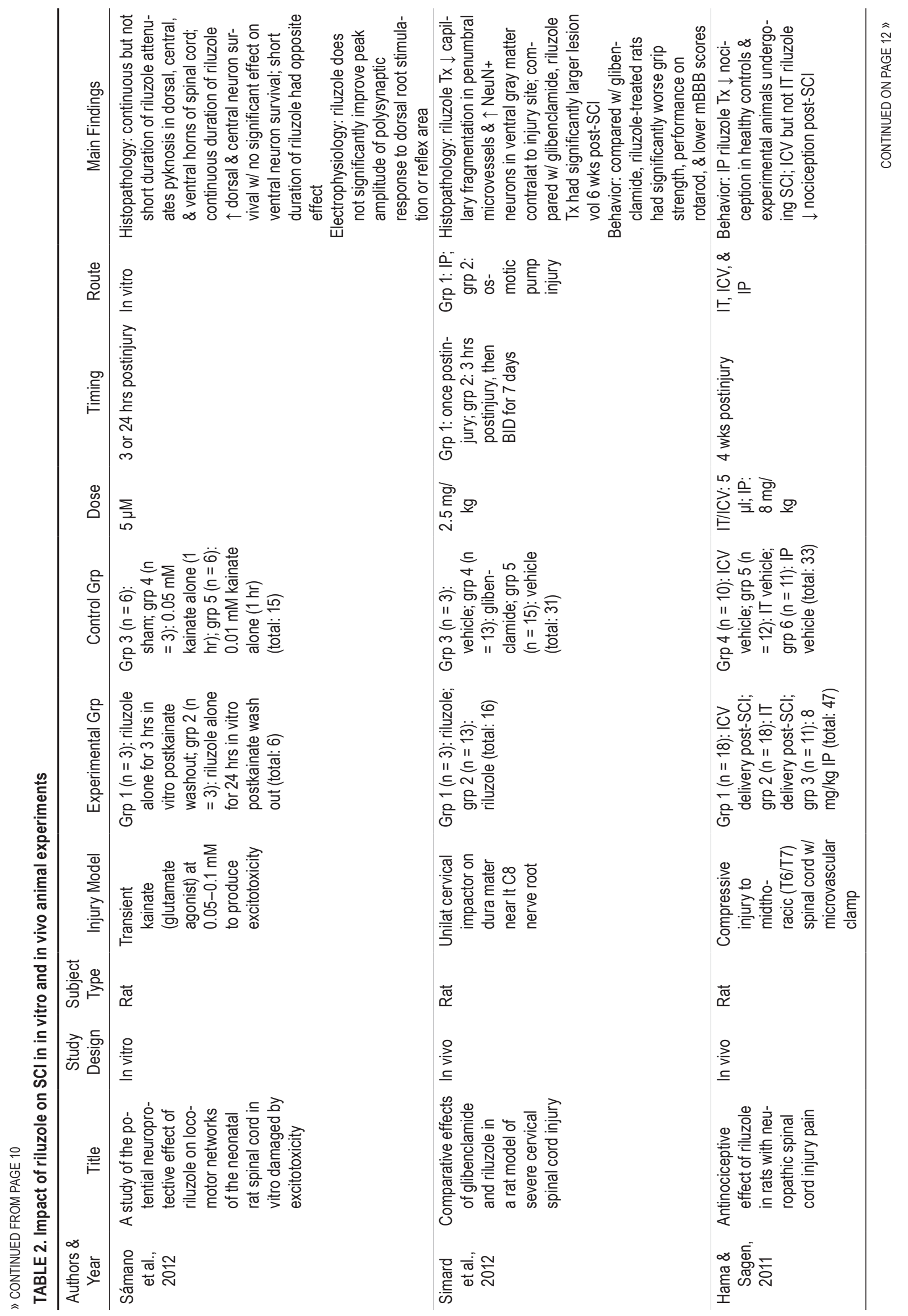




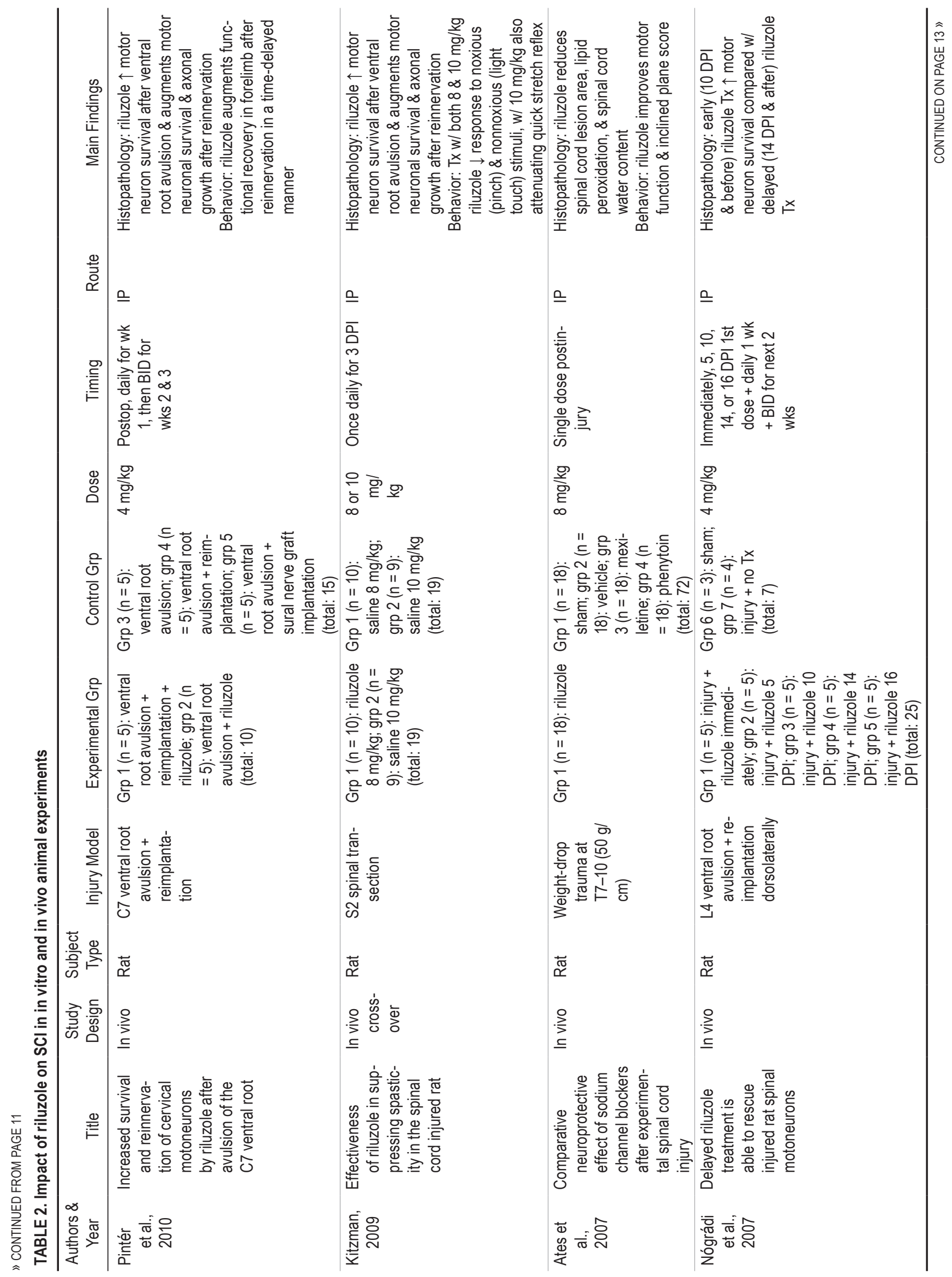




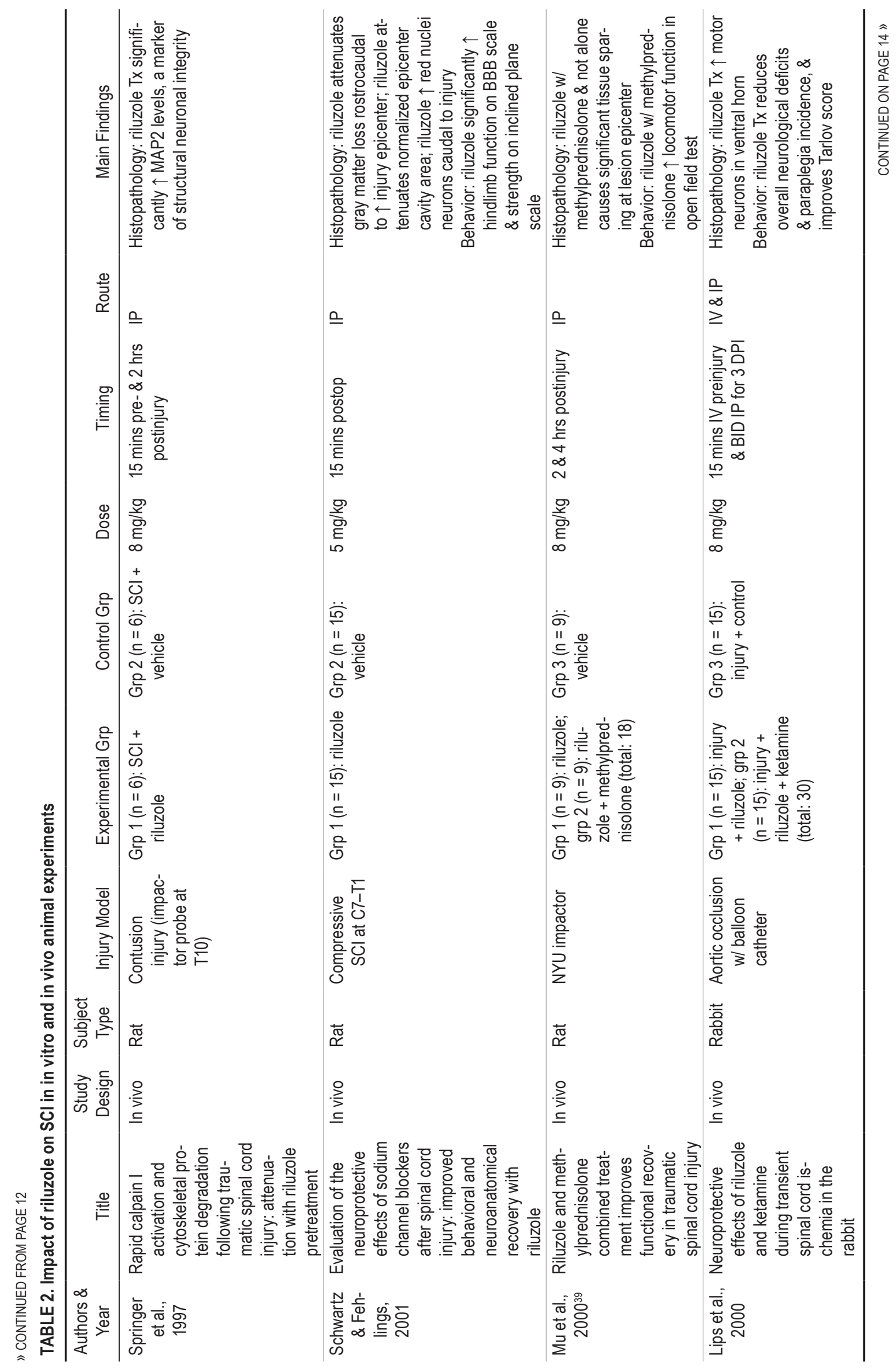




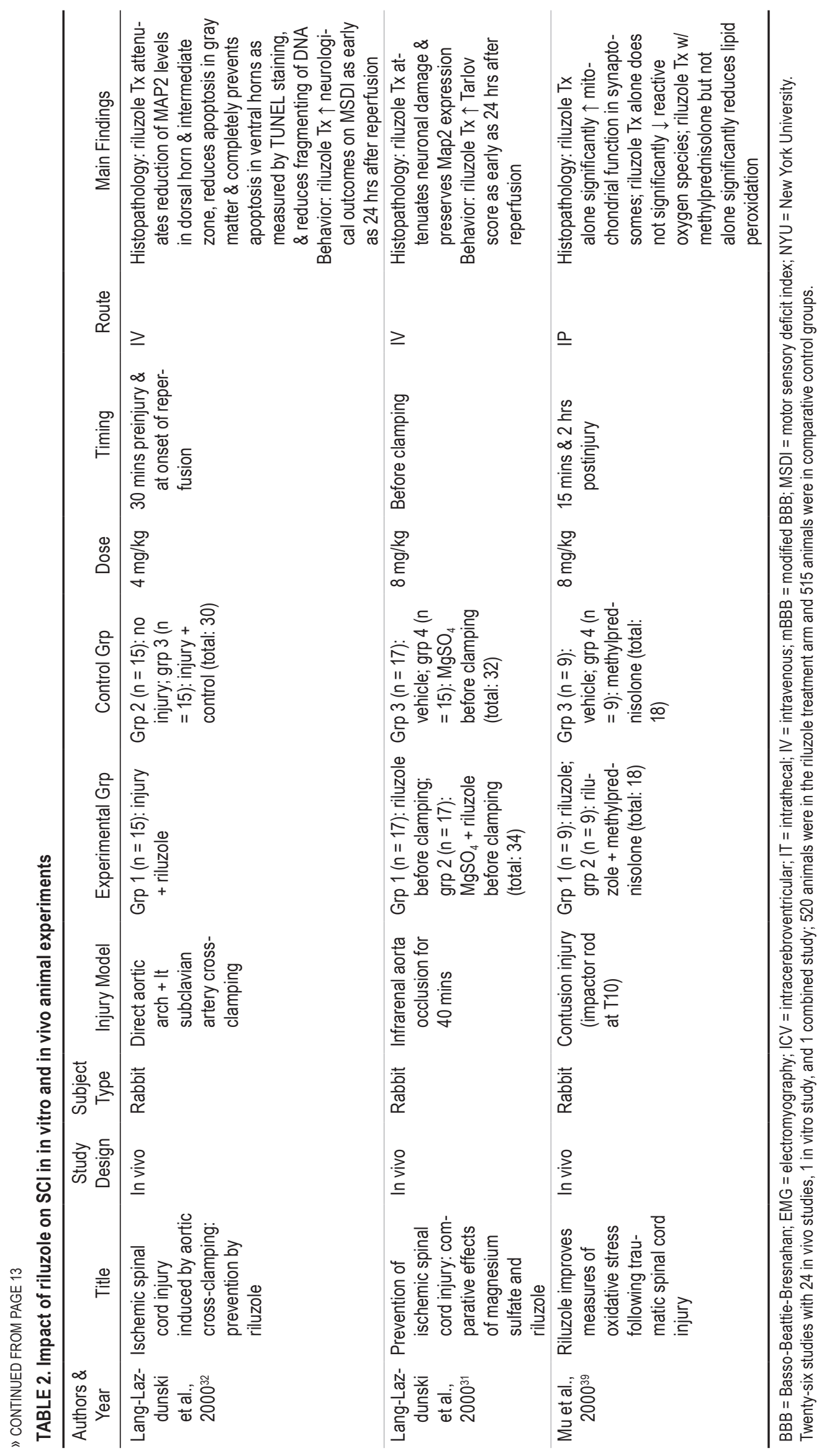




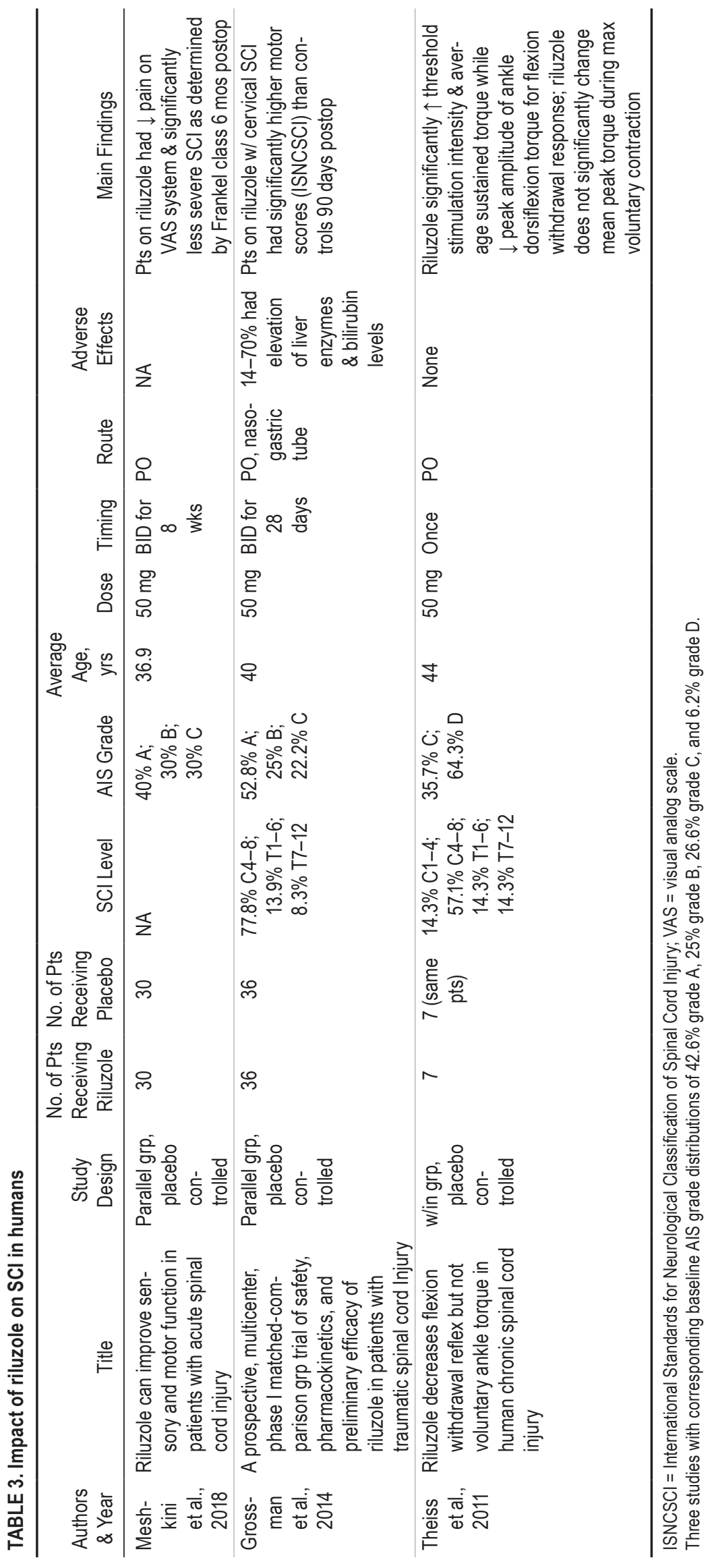


blocking presynaptic release of glutamate, and blocking persistent sodium currents. ${ }^{11}$ Of significance, in contrast to ALS where a high bioavailability $(>90 \%)$ is reported, ${ }^{9}$ riluzole in SCI in humans exhibited a lower maximum concentration and systemic exposure 0-12 hours after dosing. ${ }^{10}$ Even more importantly, in SCI, there is inflammation, which increases the spinal cord expression of $\mathrm{PgP}$, a drug efflux transporter, which decreases the bioavailability of riluzole in the spinal cord compared to plasma, so antiinflammatory medications such as COX or LOX-5 inhibitors decrease $\mathrm{PgP}$ expression and increase bioavailability of riluzole in the spinal cord. ${ }^{15}$ However, other studies have suggested that the half-life of riluzole increases with SCI and remains substantially higher in the spinal cord than in the plasma. ${ }^{58}$ The effects of riluzole seem dose-dependent, with glutamatergic uptake activity of 0.1 and $1.0 \mu \mathrm{M}$ riluzole in spinal cord synaptosomes that are not replicated at higher doses. ${ }^{2}$ Careful dose management is likely required for effective treatment of riluzole in humans. Moreover, in one pharmacological study, there was a 30\% treatmentassociated mortality with riluzole,${ }^{15}$ suggesting that despite therapeutic benefits, conservative administration of riluzole in SCI is required for most optimal results.

Within the animal studies, there were significant therapeutic benefits of riluzole manifested by increased tissue sparing, 1,6,21,30,32,33,38,39,41,44,46-49,55,57,58 decreased neuropathy, ${ }^{5,24}$ improved motor function, 1,7,21,27,32-34,38,44,47-49,55 and reduction of aberrant electrophysiology., ${ }^{5,47}$ Histological benefits of riluzole were often localized caudal to the injury epicenter. ${ }^{34,47,48,55,58}$ Specifically, riluzole decreased molecular markers of injury such as reactive oxygen species ${ }^{49}$ and immune cells,,, 58 while preserving markers of plasticity and structural integrity such as MAP2, ${ }^{32,51}$ synaptophysin, and subunits of the NMDA receptor and AMPA receptor ${ }^{47}$ This neuroprotective effect of riluzole was often augmented by other pharmacological agents, such as methylprednisolone ${ }^{38,39}$ and dantrolene. ${ }^{34}$ Moreover, several studies demonstrated dose-dependent, ${ }^{5}$ time-dependent, ${ }^{41,46}$ and route-dependent ${ }^{24}$ efficacy of riluzole in SCI, suggesting that dose, timing, and route are important factors to consider in clinical SCI. While studies demonstrate poor efficacy of riluzole in select experiments-behaviorally, ${ }^{34}$ histologically, $, 23,39,50,55$ or via electrophysiological measurements ${ }^{46,50}$-no study exclusively reported negative results. Rather, the efficacy of riluzole can be subtherapeutic or inferior to other neuroprotective agents contingent on a variety of aforementioned factors.

Many studies produced negative results, with riluzole having little effect on outcomes. For example, one study showed that riluzole alone without methylprednisolone does not improve locomotion or tissue sparing. ${ }^{38}$ Likewise, another study showed that riluzole does not reduce apoptosis or increase motor function or strength after SCI. ${ }^{7}$ A similar study showed that riluzole does not affect survival or the phenotype of cells after a neural stem and progenitor cell graft. ${ }^{23}$ Sámano et al. ${ }^{46}$ suggested that there is no change in peak amplitude of polysynaptic response to dorsal root stimulation or reflex area in vivo, and no change in ventral motor neuron cell survival in vitro with riluzole. However, a variety of studies found the opposite with regard to ventral motor neuron cell survival. ${ }^{33,41,44} \mathrm{Mu}$ et al. ${ }^{39}$ suggested that riluzole does not reduce reactive oxygen species or lipid deoxidation, but the opposite was found by Shimizu et al. ${ }^{49}$ and Ates et al., ${ }^{1}$ respectively. Given the discrepancy in outcomes between animal studies, riluzole may be neuroprotective in SCI on a selective basis. For example, studies have shown that with higher doses, riluzole had longer-lasting and more effective outcomes. ${ }^{5,23}$ However, also with high doses of riluzole, adverse outcomes such as death and respiratory distress have been reported. ${ }^{58}$

Of encouragement, early clinical studies suggested that riluzole is efficacious in decreasing neuropathic pain, ${ }^{37}$ increasing motor recovery, ${ }^{22}$ and decreasing aberrant reflexes ${ }^{54}$ However, given the relatively sparse number of patients $(n=73)$ and potential hepatotoxic effects of riluzole ${ }^{22}$ in SCI, there remains a need for more robust clinical data on safety and therapeutic benefit from the phase 2 and 3 clinical trials. ${ }^{18}$ This is especially true considering the wide range of adverse effects reported with riluzole use in ALS, including hypertension, peripheral edema, pancreatitis, ${ }^{17}$ neutropenia, renal disease, interstitial lung disease, and hepatotoxicity. The use of riluzole in SCI is documented far more extensively in animal models than in humans. Given this disparity in total subjects, animal studies have greater power, and the neuroprotective effects of riluzole after SCI in animals are well known. As more patients are enrolled in the ongoing phase 2 clinical trial, the effects of riluzole on motor, sensory, and neurological function will become better understood. ${ }^{18}$ Thus, the primary limitation of this review includes extrapolation of animal data to the clinical efficacy of riluzole. Moreover, the most common adverse effects of riluzole are described more extensively in ALS than in SCI. According to the National Spinal Cord Injury Center, life expectancy for patients with SCI remains significantly lower than for those without SCI, and this disparity has not been improving since the $1980 \mathrm{~s} .{ }^{40}$ Given the astronomical inpatient and outpatient costs associated with SCI, ${ }^{20}$ improving patient outcomes with neuroprotective agents can decrease cost and improve quality of life.

\section{Conclusions}

The neuroprotective effects of riluzole in SCI are promising, but the therapeutic benefit of riluzole in SCI must be appreciated in the appropriate clinical context. Success in animal models does not always translate to success in humans. While preliminary human studies suggest that riluzole may have a role in decreasing neuropathic pain and improving motor recovery for patients with SCI, there remains a need to substantiate these data with consistently reported clinical studies. However, other studies have demonstrated adverse effects, including pancreatitis, lung disease, and neutropenia, without conferring much clinical benefit. As the drug advances through the subsequent clinical trial stages, it will be important to titer the dose and timing to maximize benefits in appropriately selected patients to minimize adverse or ineffective outcomes. Nevertheless, these efforts provide the opportunity to expand the existing, limited pharmacological treatment options to mitigate the devastating effects of SCI and to offer patients the possibility of medical options to improve longterm function and pain control. 


\section{References}

1. Ates O, Cayli SR, Gurses I, Turkoz Y, Tarim O, Cakir CO, et al: Comparative neuroprotective effect of sodium channel blockers after experimental spinal cord injury. J Clin Neurosci 14:658-665, 2007

2. Azbill RD, Mu X, Springer JE: Riluzole increases high-affinity glutamate uptake in rat spinal cord synaptosomes. Brain Res 871:175-180, 2000

3. Bartholdi D, Schwab ME: Methylprednisolone inhibits early inflammatory processes but not ischemic cell death after experimental spinal cord lesion in the rat. Brain Res 672:177186,1995

4. Bellingham MC: A review of the neural mechanisms of action and clinical efficiency of riluzole in treating amyotrophic lateral sclerosis: what have we learned in the last decade? CNS Neurosci Ther 17:4-31, 2011

5. Brocard C, Plantier V, Boulenguez P, Liabeuf S, Bouhadfane M, Viallat-Lieutaud A, et al: Cleavage of $\mathrm{Na}^{+}$channels by calpain increases persistent $\mathrm{Na}^{+}$current and promotes spasticity after spinal cord injury. Nat Med 22:404-411, 2016

6. Caglar YS, Demirel A, Dogan I, Huseynov R, Eroglu U, Ozgural O, et al: Effect of riluzole on spinal cord regeneration with hemisection method before injury. World Neurosurg 114:e247-e253, 2018

7. Can H, Aydoseli A, Gömleksiz C, Göker B, Altunrende ME, Dolgun $\mathrm{M}$, et al: Combined and individual use of pancaspase inhibitor Q-VD-OPh and NMDA receptor antagonist riluzole in experimental spinal cord injury. Ulus Travma Acil Cerrahi Derg 23:452-458, 2017

8. Cardenas DD, Hoffman JM, Kirshblum S, McKinley W: Etiology and incidence of rehospitalization after traumatic spinal cord injury: a multicenter analysis. Arch Phys Med Rehabil 85:1757-1763, 2004

9. Cheah BC, Vucic S, Krishnan AV, Kiernan MC: Riluzole, neuroprotection and amyotrophic lateral sclerosis. Curr Med Chem 17:1942-199, 2010

10. Chow DS, Teng Y, Toups EG, Aarabi B, Harrop JS, Shaffrey $\mathrm{CI}$, et al: Pharmacology of riluzole in acute spinal cord injury. J Neurosurg Spine 17 (1 Suppl):129-140, 2012

11. Cifra A, Mazzone GL, Nistri A: Riluzole: what it does to spinal and brainstem neurons and how it does it. Neuroscientist 19:137-144, 2013

12. David S, Kroner A: Repertoire of microglial and macrophage responses after spinal cord injury. Nat Rev Neurosci 12:388-399, 2011

13. DeVivo MJ, Chen Y, Mennemeyer ST, Deutsch A: Costs of care following spinal cord injury. Top Spinal Cord Inj Rehabil 16:1-9, 2011

14. Doble A: The pharmacology and mechanism of action of riluzole. Neurology 47 (6 Suppl 4):S233-S241, 1996

15. Dulin JN, Moore ML, Grill RJ: The dual cyclooxygenase/5lipoxygenase inhibitor licofelone attenuates p-glycoproteinmediated drug resistance in the injured spinal cord. J Neurotrauma 30:211-226, 2013

16. Dumont RJ, Okonkwo DO, Verma S, Hurlbert RJ, Boulos PT, Ellegala DB, et al: Acute spinal cord injury, part I: pathophysiologic mechanisms. Clin Neuropharmacol 24:254264, 2001

17. Falcão de Campos C, de Carvalho M: Riluzole-induced recurrent pancreatitis. J Clin Neurosci 45:153-154, 2017

18. Fehlings MG, Nakashima H, Nagoshi N, Chow DSL, Grossman RG, Kopjar B: Rationale, design and critical end points for the Riluzole in Acute Spinal Cord Injury Study (RISCIS): a randomized, double-blinded, placebo-controlled parallel multi-center trial. Spinal Cord 54:8-15, 2016

19. Fehlings MG, Wilson JR, Frankowski RF, Toups EG, Aarabi B, Harrop JS, et al: Riluzole for the treatment of acute traumatic spinal cord injury: rationale for and design of the
NACTN Phase I clinical trial. J Neurosurg Spine 17 (1 Suppl):151-156, 2012

20. French DD, Campbell RR, Sabharwal S, Nelson AL, Palacios PA, Gavin-Dreschnack D: Health care costs for patients with chronic spinal cord injury in the Veterans Health Administration. J Spinal Cord Med 30:477-481, 2007

21. Gloviczki B, Török DG, Márton G, Gál L, Bodzay T, Pintér $\mathrm{S}$, et al: Delayed spinal cord-brachial plexus reconnection after $\mathrm{C} 7$ ventral root avulsion: the effect of reinnervating motoneurons rescued by riluzole treatment. J Neurotrauma 34:2364-2374, 2017

22. Grossman RG, Fehlings MG, Frankowski RF, Burau KD, Chow DS, Tator C, et al: A prospective, multicenter, phase I matched-comparison group trial of safety, pharmacokinetics, and preliminary efficacy of riluzole in patients with traumatic spinal cord injury. J Neurotrauma 31:239-255, 2014

23. Hachem LD, Mothe AJ, Tator CH: Evaluation of the effects of riluzole on adult spinal cord-derived neural stem/progenitor cells in vitro and in vivo. Int J Dev Neurosci 47 (Pt B):140-146, 2015

24. Hama A, Sagen J: Antinociceptive effect of riluzole in rats with neuropathic spinal cord injury pain. J Neurotrauma 28:127-134, 2011

25. Harvey PJ, Li Y, Li X, Bennett DJ: Persistent sodium currents and repetitive firing in motoneurons of the sacrocaudal spinal cord of adult rats. J Neurophysiol 96:1141-1157, 2006

26. Hinchcliffe M, Smith A: Riluzole: real-world evidence supports significant extension of median survival times in patients with amyotrophic lateral sclerosis. Degener Neurol Neuromuscul Dis 7:61-70, 2017

27. Hosier H, Peterson D, Tsymbalyuk O, Keledjian K, Smith $\mathrm{BR}$, Ivanova S, et al: A direct comparison of three clinically relevant treatments in a rat model of cervical spinal cord injury. J Neurotrauma 32:1633-1644, 2015

28. Kakulas BA: Neuropathology: the foundation for new treatments in spinal cord injury. Spinal Cord 42:549-563, 2004

29. Katoh-Semba R, Asano T, Ueda H, Morishita R, Takeuchi IK, Inaguma Y, et al: Riluzole enhances expression of brainderived neurotrophic factor with consequent proliferation of granule precursor cells in the rat hippocampus. FASEB J 16:1328-1330, 2002

30. Kitzman PH: Effectiveness of riluzole in suppressing spasticity in the spinal cord injured rat. Neurosci Lett 455:150-153, 2009

31. Lang-Lazdunski L, Heurteaux C, Dupont H, Widmann C, Lazdunski M: Prevention of ischemic spinal cord injury: comparative effects of magnesium sulfate and riluzole. J Vasc Surg 32:179-189, 2000

32. Lang-Lazdunski L, Heurteaux C, Mignon A, Mantz J, Widmann C, Desmonts J, et al: Ischemic spinal cord injury induced by aortic cross-clamping: prevention by riluzole. Eur J Cardiothorac Surg 18:174-181, 2000

33. Lips J, de Haan P, Bodewits P, Vanicky I, Dzoljic M, Jacobs MJ, et al: Neuroprotective effects of riluzole and ketamine during transient spinal cord ischemia in the rabbit. Anesthesiology 93:1303-1311, 2000

34. Martins BC, Torres BBJ, de Oliveira KM, Lavor MS, Osório $\mathrm{CM}$, Fukushima FB, et al: Association of riluzole and dantrolene improves significant recovery after acute spinal cord injury in rats. Spine J 18:532-539, 2018

35. McAdoo DJ, Hughes MG, Nie L, Shah B, Clifton C, Fullwood $\mathrm{S}$, et al: The effect of glutamate receptor blockers on glutamate release following spinal cord injury. Lack of evidence for an ongoing feedback cascade of damage $\rightarrow$ glutamate release $\rightarrow$ damage $\rightarrow$ glutamate release $\rightarrow$ etc. Brain Res 1038:92-99, 2005

36. McDonald JW, Sadowsky C: Spinal-cord injury. Lancet 359:417-425, 2002

37. Meshkini A, Salehpour F, Aghazadeh J, Mirzaei F, Naseri 
Alavi SA: Riluzole can improve sensory and motor function in patients with acute spinal cord injury. Asian J Neurosurg 13:656-659, 2018

38. Mu X, Azbill RD, Springer JE: Riluzole and methylprednisolone combined treatment improves functional recovery in traumatic spinal cord injury. J Neurotrauma 17:773-780, 2000

39. Mu X, Azbill RD, Springer JE: Riluzole improves measures of oxidative stress following traumatic spinal cord injury. Brain Res 870:66-72, 2000

40. National Spinal Cord Injury Statistical Center: Spinal cord injury facts and figures at a glance. J Spinal Cord Med 35:197-198, 2012

41. Nógrádi A, Szabó A, Pintér S, Vrbová G: Delayed riluzole treatment is able to rescue injured rat spinal motoneurons. Neuroscience 144:431-438, 2007

42. Noh KM, Hwang JY, Shin HC, Koh JY: A novel neuroprotective mechanism of riluzole: direct inhibition of protein kinase C. Neurobiol Dis 7:375-383, 2000

43. Park E, Velumian AA, Fehlings MG: The role of excitotoxicity in secondary mechanisms of spinal cord injury: a review with an emphasis on the implications for white matter degeneration. J Neurotrauma 21:754-774, 2004

44. Pintér S, Gloviczki B, Szabó A, Márton G, Nógrádi A: Increased survival and reinnervation of cervical motoneurons by riluzole after avulsion of the C7 ventral root. J Neurotrauma 27:2273-2282, 2010

45. Rowland JW, Hawryluk GW, Kwon B, Fehlings MG: Current status of acute spinal cord injury pathophysiology and emerging therapies: promise on the horizon. Neurosurg Focus 25(5):E2, 2008

46. Sámano C, Nasrabady SE, Nistri A: A study of the potential neuroprotective effect of riluzole on locomotor networks of the neonatal rat spinal cord in vitro damaged by excitotoxicity. Neuroscience 222:356-365, 2012

47. Satkunendrarajah K, Nassiri F, Karadimas SK, Lip A, Yao G, Fehlings MG: Riluzole promotes motor and respiratory recovery associated with enhanced neuronal survival and function following high cervical spinal hemisection. Exp Neurol 276:59-71, 2016

48. Schwartz G, Fehlings MG: Evaluation of the neuroprotective effects of sodium channel blockers after spinal cord injury: improved behavioral and neuroanatomical recovery with riluzole. J Neurosurg 94 (2 Suppl):245-256, 2001

49. Shimizu EN, Seifert JL, Johnson KJ, Romero-Ortega MI: Prophylactic riluzole attenuates oxidative stress damage in spinal cord distraction. J Neurotrauma 35:1319-1328, 2018

50. Simard JM, Tsymbalyuk O, Keledjian K, Ivanov A, Ivanova $\mathrm{S}$, Gerzanich V: Comparative effects of glibenclamide and riluzole in a rat model of severe cervical spinal cord injury. Exp Neurol 233:566-574, 2012
51. Springer JE, Azbill RD, Kennedy SE, George J, Geddes JW: Rapid calpain I activation and cytoskeletal protein degradation following traumatic spinal cord injury: attenuation with riluzole pretreatment. J Neurochem 69:1592-1600, 1997

52. Stratman RC, Wiesner AM, Smith KM, Cook AM: Hemodynamic management after spinal cord injury. Orthopedics 31:252-255, 2008

53. Sung B, Lim G, Mao J: Altered expression and uptake activity of spinal glutamate transporters after nerve injury contribute to the pathogenesis of neuropathic pain in rats. $\mathbf{J}$ Neurosci 23:2899-2910, 2003

54. Theiss RD, Hornby TG, Rymer WZ, Schmit BD: Riluzole decreases flexion withdrawal reflex but not voluntary ankle torque in human chronic spinal cord injury. J Neurophysiol 105:2781-2790, 2011

55. Vasconcelos NL, Gomes ED, Oliveira EP, Silva CJ, Lima R, Sousa N, et al: Combining neuroprotective agents: effect of riluzole and magnesium in a rat model of thoracic spinal cord injury. Spine J 16:1015-1024, 2016

56. Wokke J: Riluzole. Lancet 348:795-799, 1996

57. Wu Y, Satkunendrarajah K, Fehlings MG: Riluzole improves outcome following ischemia-reperfusion injury to the spinal cord by preventing delayed paraplegia. Neuroscience 265:302-312, 2014

58. Wu Y, Satkunendrarajah K, Teng Y, Chow DS, Buttigieg J, Fehlings MG: Delayed post-injury administration of riluzole is neuroprotective in a preclinical rodent model of cervical spinal cord injury. J Neurotrauma 30:441-452, 2013

\section{Disclosures}

The authors report no conflict of interest concerning the materials or methods used in this study or the findings specified in this paper.

\section{Author Contributions}

Conception and design: all authors. Acquisition of data: Srinivas. Analysis and interpretation of data: all authors. Drafting the article: all authors. Critically revising the article: all authors. Reviewed submitted version of manuscript: all authors. Approved the final version of the manuscript on behalf of all authors: Pham. Statistical analysis: all authors. Administrative/technical/material support: Pham. Study supervision: Pham.

\section{Correspondence}

Martin H. Pham: University of California San Diego School of Medicine, San Diego, CA. mhpham@ucsd.edu. 